\title{
A Feminist's Call for Anarchy
}

\section{By Marlee Jacocks}

$\cos$

\section{ABSTRACT}

While Ursula Le Guin's novel The Dispossessed has been categorized as a science fiction and utopian novel, I argue that it should also be considered a feminist utopia. With influences from feminism and Marxism, Le Guin uses both theories to create a comparison between two political systemsanarchy and democracy - to ultimately reveal that anarchy is more conducive for feminism. The anarchic system of government provides women with more agency than capitalism, because women are free from class and gender oppression. Theorists such as Lewis Call and Daniel Jaeckle define the anarchy that is established in The Dispossessed. The distinct female characters in The Dispossessed demonstrate the clear differences between the two political systems. Additionally, I argue that The Dispossessed is a feminist text with the ultimate purpose of demonstrating how women can reach equality and ultimate agency in an anarchic state due to Le Guin's example. 
"A Woman's Place is In the House" flashes in bold, black font as the newly elected Congresswomen of 2019 scroll across the screen each standing confidently and proudly. These women represent an important statistic for all women in the United States; they are the 35 women who make up the most diverse class of Congress in terms of race and gender (Filipovic). Despite this progress, equal representation of women in the United States is still shockingly behind in both politics and the private sector. Furthermore, despite the continuously growing number of women who have declared a presidential run in 2020, there has still never been a female president. In any given political system, there are distinct differences and disparities between the roles of men and women. Often times women are marginalized, particularly in cultures dominated by a patriarchal system and a long-standing history of male governmental rule, as is the case in the United States. In response, feminism has moved through multiple waves over time to focus on different needs for women and other marginalized groups. Given this current context within the United States, and being a woman in leadership positions myself, I still cannot help but ask: Where are the women? Even in utopian fiction, where gender equality might be expected in an imagined perfect society, the question still stands.

Feminist utopias specifically provide an image of what an ideal world would look like in which women are actually equal to men, or in some cases a satirical perspective of a world where women are superior to men. According to William Marcellino, "feminist utopian works critique dominant male power and focus and offer some kind of imagined, idealized society that is not characterized by male power and focus" (203). Ursula K. Le Guin takes up this call in several of her novels and essays, but explicitly in The Dispossessed, in which she creates a feminist utopian society that not only emphasizes the roles of women, but also challenges the traditional conventions of a feminist utopia with a male protagonist. By comparing the role that women play in a utopian political system with their role in a traditional Western political system, Le Guin evokes a clear distinction between women's current situation and the potential for a better future. The comparison of a woman's role on the two different planets Le Guin portrays have led many scholars to read the text as a feminist utopia. The dynamics of Le Guin's ambiguous utopia allow the reader to consider women's places within different institutions, such as the anarchic state on Anarres and the capitalist society on Urras. Combining these portrayals of women and politics, I argue that capitalism fails to recognize the work 
of women and the equality they deserve, while the anarchic system of government in Ursula Le Guin's The Dispossessed fantasizes about a dissolution of patriarchal and capitalist oppression that allows for the incorporation of feminist forms of government and therefore establishes anarchy as an agential system for women while also proving that feminism is a cause for all.

The setting of The Dispossessed alternates between life on the planet Anarres and life on the planet Urras. The alternation between planets also creates a relationship between an anarchic and democratic political system that puts the two systems in constant comparison. Life first began on Urras, but the world became a dystopian society when revolutionaries began to challenge the system. Urras is a democracy that reflects the governmental system of the Western world. A woman named Odo was the leader of the revolution on Urras, and she began to form her own society. It is not just a coincidence that this society was founded by a woman, especially once more female characters are introduced to the story. Takver and Rulag are the two main female characters who guide the consideration of a feminist utopia while representing what life is like for women on Anarres, with Odo setting the foundation. After a revolution, the Odonians left Urras to form their new society on what is technically the moon of Urras. This moon became Anarres and they became the Odonian society. This process is what establishes the utopian context of The Dispossessed. The cause for revolution pushed Odonians to think about a more ideal world, and when given the chance to start a new society, they created a utopia.

Anarres is the planet on which the protagonist, Shevek, lives with his partner Takver and their two children. Their way of life is defined by the anarchic system that dominates Anarres. Lewis Call categorizes both Anarres and Le Guin herself as proponents of anarchy. In the simplest terms, anarchy is often defined as a system with no government. There are no laws and no overarching institution of power which governs society. Anarchy as a political and philosophical theory began around the early nineteenth century and challenged the oppression from capital and the state (Call 87). As the definition of anarchy evolved through the twentieth century, ethnic power and gender power were added to the forms of oppression that anarchy sought to dispel (Call 87). The Dispossessed is categorized as an anarchist state because the people of Anarres are "free of the inequalities of capitalism and the injustices of state power" (Call 88). For example, there is no 
distinction between male or female names, which helps to eliminate any gender bias or prejudice that might normally exist. There is no way to tell, based off of a name, whether a character is a man or a woman. Furthermore, there is freedom from class oppression because labor is assigned randomly through the means of a computer system in order to ensure there is no distinction of class. Le Guin creates a utopian society on the foundational elements of anarchy-no central government and freedom from oppression.

The form of anarchy Le Guin creates is considered by Daniel Jaeckle to be "a highly traditional anarchist society" (75). This includes freedom from the state as Call identifies, but Jaeckle also defines anarchy in terms of freedom from "organized religion, and private property" (75). On Anarres, there is both a sense of individuality as the people exercise their own free will, but also a great sense of responsibility to maintain a functioning society without an overarching form of government. Social and political power are neither desired nor valued on Anarres, because they are considered repressive rather than agential. As Jaeckle claims, Anarres functions with "no government, church, or ruling class" (76). To the Western reader who is accustomed to a highly systematic form of government and way of life, the utopian anarchy seems initially difficult to imagine.

Despite this claim of difficulty, Le Guin provides copious details to help the audience understand life on Anarres, and more specifically, how a society can still function effectively and efficiently with no government through decentralization. Odo's main goal when starting a new society on Anarres was decentralization-to move away from large or central governments to smaller organizations. Furthermore, Shevek describes how "the network was not to be run from the top down. There was to be no controlling center, no capital, no establishment for the self-perpetuating machinery of bureaucracy" (Le Guin 95). The people of Anarres were successful in fulfilling Odo's plans for society. There is no form of currency on Anarres and society is largely communal. If an Anarresti is not copulating or partnering, then they sleep in dormitories. Meals are served in dining courts and each territory receives the "same share and share alike for food" mentality (Le Guin 111).

This communal style of living is maintained through education. It is ingrained in the minds of children at a young age that, "Nothing is yours. It is to use. It is to share. If you will not share it, you cannot use it" (Le Guin 27). The emphasis on sharing is what allows Anarres to maintain an anarchic 
system. The lessons taught to children are determined and administered by the single challenge to Le Guin's anarchic state-the Production and Distribution Coordination (PDC). This is the only system on Anarres that would closely relate to any form of government. The PDC is a "network of administration and management" that functions for the purpose of assigning jobs (76). Even though the PDC seems to resemble a type of government, Shevek makes it clear that the PDC "do not govern persons; they administer production" (76). In this sense, Le Guin is successful in creating and establishing an anarchic system.

Le Guin, in essence, offers an alternative to the capitalism that permeates every aspect of Western government. Tim Libretti argues that Le Guin's portrayal of a utopian society is "radically different from contemporary U.S. capitalist society" so that Le Guin is able to fully address "the question of human nature" as a means to represent a utopian society as a possibility (308). In other words, Le Guin recognizes human nature, with an influence from Marxism, as being characterized "by an imaginative drive to create" rather than to work or make a profit (306). This is evident from Le Guin's own writing in her article "Why are Americans Afraid of Dragons?” which explains how "work" is defined in the U.S. capitalist society. "Dragons," in the context of Le Guin's article, represent fantasy and imagination. To answer the question in her title, Le Guin argues that Americans are afraid of these "dragons," because they fear the pleasure that fantasy and imagination provide, because this pleasure takes away from the focus and emphasis on work ("Dragons"). In capitalism, life is defined by work. Anarchy is defined by its contrast with capitalism because of its opposition to the capitalist mindset that prevents people from freedom. Marxism influences this definition of anarchy to set the foundation for a life that is not entirely determined by work. According to Le Guin, freedom comes with imagination, which she defines as "the free play of the mind, both intellectual and sensory" ("Dragons"). Essentially, creativity and unrestraint are what provide freedom, but these elements cannot be found in capitalism, thus Le Guin turns to anarchy as a utopian model.

The anarchic system that Le Guin creates in The Dispossessed not only creates a society with more freedom, but it also especially provides women with more freedom and agency. According to Le Guin, the inability to employ imagination in the context of capitalism is a challenge for men. Many men in America have "learned to repress their imagination" and "to fear it," which has consequently 
prevented them from experiencing pleasure and delight (Le Guin "Dragons"). This lack of pleasure and delight is one of the ways in which the capitalist society in the United States is persistently supported and maintained.

Anarchy in The Dispossessed calls into question these elements of capitalism and reveals their harmful nature to women, while providing a better alternative. Le Guin's text ultimately becomes a feminist piece as she provides women with the utmost agency by dispelling and eliminating capitalist barriers in an anarchic system. The system of capitalism is riddled with faults that have proven to create lasting disparities, especially in regard to gender. The system infringes upon multiple individual freedoms, but the greatest discrepancy lies in the treatment of more than half the population-women. Capitalism was created by men to be implemented in a patriarchal society. It fails to take into consideration the work of women publicly and privately, while providing them with little to no agency to receive the same freedoms that men experience. Essentially, capitalism forgets women, especially when considering reproduction. The most glaring fault of capitalism is that it does not recognize the fact that through the means of reproduction women are responsible for supplying the laborers who produce and create capital. Even more, reproduction in and of itself is a form of labor, but capitalism does not acknowledge this significant and necessary work on the part of women.

With influence from Marxism and the 1970s "Women in Work" movement, Le Guin is provided a platform to challenge capitalism's oppression of class and gender. Erik Wright defines Marxist theory, as well as feminist theory, as "emancipatory theoretical traditions in that they envision the possibility of eliminating certain forms of oppression from social life" (39). In relation to The Dispossessed, Marxism is the first step to anarchy because it identifies anarchy as the end goal. In order to be liberated, the people must first reject capitalism, then enter a state of socialism that eventually gives way to an anarchic system. Anarchy is the goal because, according to Marxism, it allows for the most freedom. Marxist theory focuses specifically on freedom from class oppression and envisions a classless society, but it fails to take into consideration the place of women when envisioning this ideal society. Marxist feminist movements have realized this discrepancy and the "Wages for Housework" movement started the demand for women to be paid in the workplace as well as for their labor in the home in terms of "child care, cleaning, emotional support, even sex" (Jaffe). 
Le Guin manages to do what capitalism and Marxism fail to do for women and provides the "Wages for Housework" movement with a model society in her depiction of the anarchist Anarres.

The Dispossessed provides an alternative reality with perceived feminist ideals, but Le Guin puts pressure on the common notions of a utopia by subtitling her novel an "ambiguous utopia." The power is thus placed in the hands of the readers as Le Guin experiments with what really constitutes a utopia. She envisions "what an inhabitable, ideal society might look like," according to Jim Jose, as is usually the utopian process (180). Jose describes Le Guin's ideal society as consisting of "a political life based upon consent" and a "non-sexist and non-racist, essentially egalitarian" society (180). The anarchic system on Anarres establishes a political life based upon consent by allowing individuals to govern themselves rather than be governed. Jobs are considered work assignments, and they are determined by PDC based on the need and benefit to society (Le Guin 48). Work is not defined in terms of gender either, as women and men are assigned to jobs alike.

This is most evident in the way in which Takver, Shevek's partner, and Rulag, Shevek's mother, treat their work. Traditional roles in patriarchal society determine that the man works to support the family while the woman stays home to care for the children and do domestic work. Le Guin directly challenges these traditional gender roles. When Shevek is finishing school, he notices that the girls in his class "wanted to complete their training and start their research or find a post they liked" (Le Guin 55). Takver is one of these girls and is studying biology. When she and Shevek begin their partnership, Takver works as a "fish geneticist," essentially researching ways of increasing fish for food (Le Guin 185). Not only does Takver have a job she is passionate about, but she excels at it. She runs her own research projects, and contrary to traditional gender roles, Takver is the one who often works more hours and spends more time at the office for her work when compared to Shevek's posting assignment (Le Guin 187). This only occurs, however, because of the anarchic system, which provides women with more freedom to work as they wish. Takver does not have to fill the traditional role of a woman staying at home to clean and raise their children, because these tasks are eliminated by the anarchic system. On Anarres children are raised in a communal setting where it is someone's job to teach and care for the children. Thus, Takver is able to work without the burden of domesticity, because the anarchic system eliminates the traditional roles of the patriarchal system. 
Le Guin also portrays the increased freedom of women in an anarchic system in terms of work through the character Rulag. Growing up on Anarres, children are sent to school where they learn with other children their age. They sleep in dormitories and spend all their days in these schools, because under anarchy, there is no concept of individual possession, even in the sense that birth parents are not responsible for raising their own children. Partners have the option of keeping their children at home when they are young, but by a certain age, partners are no longer the main caregivers for their children. This familial system is particularly freeing for women. Shevek's mother left at an early age, and while this caused some abandonment issues for Shevek, it was perfectly normal and expected in society on Anarres. For the Western reader, though, Shevek's abandonment issues work to set-up a critique of our own gendered proprietary assumptions about child rearing. This system of anarchy, in comparison to the patriarchal and capitalist system, reveal how women do not have to be responsible for the traditional child rearing roles. Instead, women are provided with every opportunity to focus on their work and not be solely responsible to care for their children. For Rulag, "work comes first ... It has always come first" and anarchy is what made this possible for Rulag to do just that (Le Guin 123). The communal, anarchical system on Anarres provides women with more agency than the patriarchal, democratic system of the United States.

Le Guin makes this distinction between the two systems most obvious with Shevek's visit to Urras, the neighboring planet of Anarres. Susan Benfield claims that "through Shevek's observations of Urras, Le Guin paints a vivid picture of the abuses and inequities to which centralized government that is based on the protection of property is prone" (128). Urras is everything that Anarres is not. The political system on Urras closely relates to the democratic and capitalistic system of the United States. As Shevek travels around Urras and meets more people, the true distinction between women on Urras and Anarres is evidently presented. On Urras, women have little to no freedom or agency.

When Shevek arrives on Urras, he asks the same question proposed at the beginning of this paper: Where are the women? More specifically, Shevek asks "why there were no women on the ship" used to travel from planet to planet, and the response is that "running a space freighter was not women's work" (Le Guin 16). The comparison is obvious then, that work on Urras is far different than work on Anarres. The distinction becomes even clearer when the man from Urras asks Shevek, "Is it 
true, Dr. Shevek, that women in your society [Anarres] are treated exactly like men?” (Le Guin 16). Such a question defines the perception and treatment of women on Urras. On Anarres, Shevek worked alongside other scientists who were women, but on Urras there are no female scientists or teachers (Le Guin 73). In fact, women rarely work on Urras, which fulfills the standard established by both capitalism and the patriarchy.

The capitalist expectation of women is defined and surrounded by domesticity, with no actual expectation of work or power, whereas women on Anarres are expected to do their fair share of the work. While on Urras, Shevek meets Vea, and she becomes the main representation of women on Urras, just as Takver and Rulag are the representation of women on Anarres. Vea is married to a wealthy man who travels regularly for work. With her husband's money and his regular absences, and without having to work herself, it initially appears as though Vea possesses a sense of freedom. This appearance is merely an illusion, though. As Shevek attempts to learn from Vea about the position of women, Vea challenges the notion that women on Urras are inferior to men. She claims that she is able to do what she likes to do, and more specifically, that the women actually run the men on Urras (Le Guin 215). While Vea may think she influences the men, it is clear that she does not, and her perceived freedom on Urras is misperceived. She does not actually possess any agency and is instead limited by the political system dominated by men.

Furthermore, unlike the women on Anarres, Vea is entirely characterized and defined by her role as a woman. This is represented by the focus on Vea's physical appearance. Shevek introduces Vea by describing how "Her breasts, shoulders, and arms were round, soft, and very white" (Le Guin 196). When Shevek sees Vea again in another interaction, he notices "Vea's slender feet, decorated with little white shoes on very high heels" (Le Guin 212). Each description of Vea resembles the literary device called a blazon - where the female body is compartmentalized in terms of its description. The female body is catalogued to redefine her as a material object that is the sum of her parts. Takver recognizes this characterization of women on Urras and sees them as "women who used their sexuality as a weapon in a power struggle with men" (Le Guin 212-213). As Shevek goes on to describe Vea, he says that "She was so elaborately and ostentatiously a female body that she seemed scarcely to be a human being" (Le Guin 213). Shevek's thoughts reveal how women like Vea on Urras 
are treated like objects. There is no description of their mind and their capabilities, rather these women are broken into pieces based off of over-sexualized descriptions from men. Vea is merely a body, and as Shevek reveals, it is difficult to see Vea for the human she is. Essentially, as a woman on Urras, Vea is a piece of property and an object to be owned by men. Shevek recognizes this, as he reminds Vea that "you know that in the eyes of men you are a thing, a thing owned, bought, sold" (Le Guin 215). With his Anarres background, Shevek is able to clearly see through the illusion of Vea's self-proclaimed agency. Through Shevek's bluntly honest reflections of women on Urras, Le Guin characterizes Urras as a planet dominated by men with a political system also focused on men.

Vea then serves to highlight the stark contrast between women on Anarres and Urras. While Vea is under the false impression that she possesses agency and freedom as a woman of Urras, her message is significant to establishing The Dispossessed as a feminist text. Shevek asks what it is Vea does and she replies, "Why, run the men, of course!" (Le Guin 215). The significance in this quotation lies in the challenge it presents to the patriarchal society on Urras. According to the men, they are in power and rule the women, but unbeknownst to them, there are women willing to challenge their power. In The Dispossessed, this woman was Odo, but outside of the utopian realm, this woman is Ursula Le Guin herself.

The contrast between Takver on Anarres and Vea on Urras represents the exact elements and goals of a feminist utopia according to Carol Pearson in that "feminist utopian fiction usually begins by showing how women are profoundly alienated and limited by patriarchal society; they then go on to acquaint the reader with an alternative potential" (50). Vea, and the few other women Shevek interacts with on Urras, appear largely alienated and ultimately dispossessed when compared to the inclusive society that consists solely of men. In contrast, the position of Takver on Anarres seems far more freeing and appealing for women, especially in terms of an alternative to Urras. The chapters of The Dispossessed alternate between Shevek describing Urras then Anarres, and thus the narrative constantly shifts from a society in which women are inferior, to the alternative society where women are equal. This organization has the effect of creating an obvious comparison between how the world is and how the world could be.

The male narration of this story, then, supports the claim that feminism is not just a cause for 
women, by women. While this initially proposes a critique of the feminist attempt from Le Guin herself as she recognizes that, "the utopia was (both in fact and fiction) founded by a woman [i.e. Odo], the protagonist is a man; and he dominates it in...a very masculine fashion" (Jose 183). While the protagonist is indeed a man and the majority of the narrative revolves around his complicated Temporal Theory of Time, I believe that Shevek dominates in a masculine way with the purpose of further benefiting feminism. On Anarres, there is no need to defend the role of women and their equality, but on Urras, it is necessary to challenge and question the inferiority of women. Considering the status of women on Urras, though, it would be nearly impossible for a woman to go to Urras and be taken seriously for her work in science, to be treated as an equal, and to consider equality for women. Shevek is able to do so, however, because he is a man in a man's world.

Shevek is not just any man, though. Before even stepping foot on Urras, Shevek confronts the Urrasti on their notions of women. When discussing work, Shevek explains that, "A person chooses work according to interest, talent, strength-what has sex to do with that?" (Le Guin 17). Immediately, Shevek challenges the idea that women should not work certain jobs, by asking a very simple, yet revealing question. Shevek asks a question that provokes thought in the real world, not just the fictitious dystopian world of Urras. For the most part, work in the twenty-first-century United States is still defined by traditional gender stereotypes, such as nursing and teaching being femaledominated fields and business and sales being male-dominated fields. Shevek has to be the character to ask this question, because on Urras he is perceived to have the authority and credibility to present such an idea to other men.

Shevek is also a man who would not be the same without the women in his life. He makes it clear that he has been influenced by intellectual and inspiring women, and this gives a specific power to women. The senior physicist at the Institute where Shevek studies physics is a woman, and Shevek claims that she "had the best mind among them"--them being women and men (Le Guin 56). Furthermore, Shevek defends the women in his life in front of the other physicists on Urras. One of the physicists ask, "Do you find any women capable of original intellectual work, Dr. Shevek?" and he responds by telling them, "Well, it was more that they found me. Mitis, in Northsetting, was my teacher. Also, Gvarab; you know of her, I think" (Le Guin 74). This exchange is significant in that first 
Shevek recognizes that it was women who played an integral role in shaping him into the physicist he is and the theories he establishes. Shevek gives credit to women, when women on Urras receive chastisement and belittlement for their forced role of inferiority. Secondly, Shevek reveals to the Urrasti physicists that one of the Anarresti physicists they worked with was a woman. All along, they were unable to tell because of the lack of distinction between male and female names on Anarres. Knowing that a woman was writing and proving complex physics theories forces the Urrasti men to confront their belief that women are incapable of "original intellectual work" (Le Guin 74). Before learning of her gender, Oiie, a Urrasti physicist, believed that Gvarab was capable of producing intellectual work, and now that he knows Gvarab is a woman, Oiie can no longer confidently uphold his claim that women are incapable and deserve to be inferior. This one instance has the potential to critique other notions of women's incapacities harbored by the men on Urras. In his role as protagonist, Shevek provokes such critiques and provides a platform for feminism in a system dominated by male power.

Le Guin furthers Shevek's feminist platform by describing an instance of gender role reversal. Takver's job is intense, and many others are not able to do the work that she does. Shevek teaches classes and works on his theories, among a multitude of colleagues. As per the protocol on Anarres, people are required to work and complete their assignments but not to over-work themselves. Takver works outside of the home, while Shevek would often times work in the home. Sometimes Shevek would work himself to the point of fatigue, and when Takver "saw how hard Shevek was used she protested. She would have cried out as Odo's husband, Asieo, did once, 'For God's sake, girl, can't you serve Truth a little at a time?'-except that she was the girl and was unacquainted with God" (Le Guin 188). In this instance, there is a very clear gender role reversal as Shevek compares his partner to Odo's husband while also comparing himself to Odo, a woman. In doing so, Shevek is provided with an even stronger platform for feminism, because he himself has been in the position of the wife, at least metaphorically speaking. Comparing Shevek to the role of Odo allows him to use this freedom to reveal the agency women deserve and respond to the oppression women face.

To put this feminist reading in context with anarchy, then, it is the anarchic state that provides Le Guin with the freedom and flexibility to write a feminist utopia. In her article "Is Gender 
Necessary?" Le Guin says, “To me the 'female principle' is, or at least historically has been, anarchic" (qtd. in Pearson 54). She goes on to say about The Dispossessed that "I think men mostly have to learn to be anarchists. Women don't have to learn" (qtd. in Pearson 54). To put this in context with the conversation pertaining to anarchy, capitalism, and Marxism, men have to learn to be anarchists because they are accustomed to creating and implementing laws. These laws are what guide and dictate men, whereas women can separate themselves from the law because for so long they have been separated from the world of capitalism and politics. Only until recently have women truly become part of the conversation when it comes to writing and passing laws.

Pearson suggests in her analysis of women and politics in utopian texts that anarchy is potentially the result of a feminist utopia. This is to say that a feminist utopia functions best when there are no laws and no form of government to enforce any form of oppression. According to Pearson, this is the case because for women, "The socialization to serve and to sacrifice one's own needs for those of others makes it possible for women to envision a society in which people cooperate, instead of competing, and nurture instead of dominate one another" (54). This has been proven outside of utopian worlds as well. U.S. Congresswoman, and current Speaker of the House, Nancy Pelosi served on the Foreign Affairs Committee during the Kosovo war in the later 1990s. When reconstruction began after the war, Pelosi recognized the importance of including women who were survivors of rape and abuse during the war. She recognized that by strengthening the women, the family becomes stronger as a whole and is better equipped for developing a society. It took a woman to focus on cooperation and nurturing a community back to prosperity, rather than implementing competition or domination.

Feminist utopias provide an example and image of what a world would look like with more female leaders. Perhaps, it would look more like anarchy on Anarres. Society would function under the priorities of equality and cooperation. Government would not enforce laws that create divisiveness or oppress marginalized groups; rather, government would only exist in the form of a computerized system that assigns jobs. Women, and men, would be free from domestic restrictions, if they so choose, to pursue a career and focus on work. Anarchy is often times a political system that evokes sensations of fear and extreme hesitancy, but when anarchy functions successfully in its true form, 
as it is represented in The Dispossessed, then it erases images of arbitrary chaos and instead evokes a desire for freedom from oppression and the ability to live according to one's own personal rule. 


\section{WORKS CITED}

Benfield, Susan Storing. “The Interplanetary Dialectic: Freedom and Equality in Ursula Le Guin's The Dispossessed.” Perspectives on Political Science, vol. 35, no. 3, summer 2006, pp. 128 134. EBSCOhost, proxy.bsu.edu/login?url=http://search.ebscohost.com/login.aspx?direct=tru $\mathrm{e} \& \mathrm{db}=\mathrm{aph} \& \mathrm{AN}=23155585 \&$ site $=$ ehost-live\&scope $=$ site.

Call, Lewis. "Postmodern Anarchism in the Novels of Ursula K. Le Guin." SubStance, vol. 36, no. 2, 2007, pp. 87-105. JSTOR, www.jstor.org/stable/25195127.

"History of Women Governors." Rutgers Center for American Women and Politics, 2019, http:// www.cawp.rutgers.edu/history-women-governors. Accessed 14 January 2019.

Donawerth, Jane. "Utopian Science: Contemporary Feminist Science Theory and Science Fiction by Women.” NWSA Journal, vol. 2, no. 4, 1990, pp. 535-557. JSTOR, www.jstor.org/ stable/4316070.

Filipovic, Jill. “A Woman’s Place is in the House.” Elle, 4 December 2018, https://www.elle.com/ culture/career-politics/a25310446/congresswomen-2018/. Accessed 14 January 2019.

Jaeckle, Daniel P. “Embodied Anarchy in Ursula K. Le Guin's: The Dispossessed.” Utopian Studies, vol. 20, no. 1, Mar. 2009, pp. 75-95. EBSCOhost, proxy.bsu.edu/login?url=http://search. ebscohost.com/login. aspx?direct=true\&db=aph\&AN=44266973\&site=ehost-live\&scope=site.

Jaffe, Sarah. “The Factory in the Family.” The Nation, 9 April 2018, https://www.thenation.com/ article/wages-for-houseworks-radical-vision/. Accessed 11 February 2019.

Jose, Jim. "Reflections on the Politics of Le Guin's Narrative Shifts (Réflexions Concernant La Politique Des Variations Narratives De Le Leguin).” Science Fiction Studies, vol. 18, no. 2, 1991, pp. 180-197. JSTOR, www.jstor.org/stable/4240058.

Le Guin, Ursula. “Why are Americans Afraid of Dragons?” The Language of the Night, edited by Susan Woods, G.P. Putnam's Sons, 1979, pp 39-46.

Libretti, Tim. "Dispossession and Disalienation: The Fulfillment of Life in Ursula LeGuin's The Dispossessed." Contemporary Justice Review, vol. 7, no. 3, Sept. 2004, pp. 305-320. EBSCO 


\section{WORKS CITED}

host, doi:10.1080/1028258042000266022.

Marcellino, William. "Shadows to Walk: Ursula Le Guin's Transgressions in Utopia.” Journal

of American Culture, vol. 32, no. 3, Sept. 2009, pp. 203-213. EBSCOhost, doi:10.1111/j.1542734X.2009.00711.x.

Pearson, Carol. “Women's Fantasies and Feminist Utopias.” Frontiers: A Journal of Women Studies, vol. 2, no. 3, 1977, pp. 50-61. JSTOR, www.jstor.org/stable/3346349.

Wright, Erik Olin. "Explanation and Emancipation in Marxism and Feminism.” Sociological Theory, vol. 11, no. 1, 1993, pp. 39-54. JSTOR, https://www.jstor.org/stable/201979. 